\title{
Multicenter, open-label, two-arm pilot trial for safety reduction of basal insulin dose combined with SGLT2 inhibitor in type 1 diabetes mellitus: A study protocol for RISING-STAR
}

\section{Masahide Hamaguchi ( $\nabla$ mhama@koto.kpu-m.ac.jp )}

Kyoto Prefectural University of Medicine, Graduate School of Medical Science https://orcid.org/00000002-8651-4445

Yoshitaka Hashimoto

Kyoto Prefectural University of Medicine

Toru Tanaka

Japanese Red Cross Kyoto Daiichi Hospital

\section{Goji Hasegawa}

Japanese Red Cross Kyoto Daini Hospital

Michiyo Ishii

Otsu City Hospital

Hiroshi Okada

Matsushita Memorial Hospital

Kazuteru Mitsuhashi

Fukuchiyama City Hospital

Noriyuki Kitagawa

Kameoka Municipal Hospital

Emi Ushigome

Kyoto Prefectural University of Medicine

Masahiro Yamazaki

Kyoto Prefectural University of Medicine

Michiaki Fukui

Kyoto Prefectural University of Medicine

\section{Study Protocol}

Keywords: type 1 diabetes mellitus, SGLT2 inhibitor, insulin dose, hypoglycemia, ketone body, ketosis, ketoacidosis

Posted Date: November 5th, 2020 
DOI: https://doi.org/10.21203/rs.3.rs-52292/v2

License: (c) (1) This work is licensed under a Creative Commons Attribution 4.0 International License. Read Full License 


\section{Abstract}

Background SGLT2 inhibitor combined with insulin is a novel therapy for patients with type 1 diabetes mellitus. Without the reduction of basal insulin, hypoglycemia could occur frequently in this therapy. However, ketoacidosis is an undesirable adverse effect in cases with basal insulin reduction.

Methods This was a multicenter, open-label, two-arm study. Sixty subjects with type 1 diabetes mellitus were recruited from 7 hospitals. Subjects whose basal insulin daily dose to total daily insulin dose (TDD) ratio was $<0.4$ were instructed not to reduce the basal insulin dose but to reduce the bolus insulin dose by $10 \%$ (Group $A$ ), and subjects with a basal-to-TDD ratio $>0.4$ were instructed to reduce the basal insulin dose by $10 \%$ (Group B). We hypothesized that the frequency of hypoglycemia would be reduced in Group $B$. The primary outcome was the frequency of hypoglycemia per day during the intervention period (administration of SGLT2 inhibitor) as determined by self-monitoring of blood glucose (SMBG). The baseline number of hypoglycemic attacks was set at $7 \pm 6$ times/month. The minimum sample size required to achieve a significance of 0.05 for a one-sided t-test with a statistical power of $80 \%$ was determined. When the sample size was 26 patients in one group, the percent increase in hypoglycemia was more than $60 \%$; thus, the sample size was estimated to be sufficient. The secondary outcome was the frequency of ketosis before and after the intervention. We aimed to confirm that the frequency of ketosis does not increase in Group B compared with Group A. The frequency of adverse events, including the frequency of hypoglycemia detected using flash glucose monitoring (FGM), was set as the safety endpoint.

Discussion The RISING-STAR study will contribute results from a two-arm randomized trial in which a reduction in basal insulin dose is indicated or no reduction in basal insulin dose is instructed for concomitant use of SGLT2 inhibitors in patients with type 1 diabetes to prevent the development of hypoglycemia.

Trial registration Registered with the Japan Registry of Clinical Trials (jRCTs051190114) on March 2, 2020.

\section{Background}

Type 1 diabetes mellitus is a disorder characterized by absolute insulin deficiency, mainly due to autoimmune-mediated pancreatic $\beta$-cell destruction. Although the cause of pancreatic $\beta$-cell destruction has not been completely elucidated, susceptibility genes and environmental factors have been implicated [1]. The number of patients with type 1 diabetes and absolute insulin deficiency is estimated to be approximately $100,000-140,000$ in Japan. The age of onset is mainly in childhood to adolescence, and in Japan, the incidence rate in persons aged $0-19$ years is 4.4/1000 [2].

Because the hallmark of type 1 diabetes is absent or near-absent $\beta$-cell function, insulin treatment is essential for individuals with type 1 diabetes [3]. Insufficient insulin causes not only hyperglycemia but also systematic metabolic disturbances, such as hypertriglyceridemia and ketoacidosis as well as tissue 
catabolism [3]. Over the past three decades, evidence has accumulated supporting multiple daily injections of insulin or continuous subcutaneous administration through an insulin pump to provide the best combination of effectiveness and safety for people with type 1 diabetes [3]. Insulin therapy consists of basal insulin to maintain stable blood glucose levels and bolus insulin to control postprandial hyperglycemia and to correct hyperglycemia if necessary. Patients with type 1 diabetes who are unable to secrete insulin are recommended to set proper amounts of basal insulin. According to the literature, the total basal insulin dose is $\sim 50 \%$ of the total daily insulin dose (TDD) [4-7]. Recently, Kuroda et al. investigated basal insulin requirement in C-peptide-negative patients with type 1 diabetes [7]. They showed that the basal insulin requirement is $\sim 30 \%$ of the TDD in inpatients on diets prepared by a dietitian [7]. In addition, the maximal basal insulin requirement in all patients was $43.8 \%$ of the TDD, and no patient required $50 \%$ of the TDD [7]. King also recently suggested that this should be revised to TBD = $0.4 \times$ TDD to prevent excess basal insulin treatment [8].

Injectable and oral glucose-lowering drugs have been studied for their efficacy as adjuncts to insulin treatment of type 1 diabetes [3]. Therapy with only insulin may cause increased body weight, especially in patients with type 1 diabetes and excess carbohydrate intake, which increases the risk of macrovascular complications [9]. On the contrary, although low-carbohydrate diets can reduce the total insulin dose and the number of self-injections, they could result in nutritional imbalances [10]. The increased mean body mass index (BMI) reported in patients with type 1 diabetes [11] additionally increases the risk of cardiovascular disorders. Sodium-glucose co-transporter (SGLT)-2 inhibitors reduce hyperglycemia via insulin-independent mechanisms by increasing glucose elimination via the kidneys [12]. Recently, an SGLT2 inhibitor, dapagliflozin, in combination with insulin therapy, was approved for type 1 diabetes [12]. Eight clinical trials were published using SGLT2 inhibitors as adjunctive therapy for type 1 diabetes, in which HbA1c, insulin dose, and body weight were decreased [13-19]. The addition of an SGLT2 inhibitor to insulin therapy has been associated with improvements in $\mathrm{A} 1 \mathrm{C}$ and body weight when compared with insulin alone [20-23]. Thus, SGLT2 inhibitors prevent cardiovascular complications in patients with type 1 diabetes mellitus, similar to that reported in patients with type 2 diabetes mellitus [14, 24].

However, SGLT2 inhibitor use is also associated with more adverse events, including hypoglycemia and ketoacidosis. It is difficult to prevent ketoacidosis or lower the risk of hypoglycemia in real-world practice. Hypoglycemia is an important determinant of glycemic control in the treatment of type 1 diabetes [25]. Many patients with type 1 diabetes struggle to achieve glycemic control and experience significant fluctuations in blood glucose levels despite insulin treatment $[12,26]$. Across randomized trials, SGLT2 inhibitors have demonstrated significant reductions in glycated hemoglobin, glucose exposure, and measures of glycemic variability, as well as increased time in the target glycemic range when administered as an adjunct to insulin [12].

To prevent hypoglycemia, many patients with type 1 diabetes reduce their basal insulin dose, which might impact glycemic control. While the addition of SGLT2 inhibitors might reduce the risk of hypoglycemia, their use has been reported to increase the frequency of ketoacidosis [17]. Therefore, reducing the insulin dose to prevent hypoglycemia during adjunctive SGLT2 inhibitor treatment may increase the risk of 
ketoacidosis, whereas maintaining the same insulin dose to prevent ketoacidosis may increase the risk of hypoglycemia. An algorithm for insulin adjustment would be beneficial when combining SGLT2 inhibitor treatment with insulin in patients with type 1 diabetes mellitus.

Therefore, we aimed to explore whether the reduction of the basal insulin dose combined with SGLT2 inhibitor in patients with type 1 diabetes could reduce the frequency of hypoglycemia. We hypothesized that, with an adequate basal insulin dose, the frequency of hypoglycemia would be higher if the basal insulin dose was not reduced when combined with an SGLT2 inhibitor.

\section{Methods And Analysis}

\section{Study protocol}

The RISING-STAR study started on March 2, 2020 with protocol version 1.1. The recruitment was completed on August 31, 2020.

This was a multicenter, open-label, non-randomized, exploratory, prospective, interventional study (Figure 1). The study was conducted at the University Hospital Kyoto Prefectural University of Medicine as the core facility and at six facilities with specialized diabetes outpatient services located in the same Kansai area in Japan as the core facility. No changes to the methods after pilot trial commencement, including eligibility criteria, have been planned. Subjects were stratified into two groups based on the ratio of basal insulin (Basal) to TDD (Basal/TDD, $<0.4$ [Group A] or $\geq 0.4$ [group B]). At the time of obtaining consent, participants were asked about their insulin use in the previous $24 \mathrm{~h}$, with respect to basal and additional insulin amounts for the previous day. The sum of the basal and additional insulin doses was defined as the total insulin dose. If the basal insulin dose was $40 \%$ of the total insulin dose, the participant was assigned to Group B. If the basal insulin dose was less than $40 \%$ of the total insulin dose, the participant was assigned to Group A. Instructions provided to the study subjects are found in Table 1.

\section{Table 1. Therapy protocol}


1 Insulin self-titration according to the algorithm

2 Recommendation to drink water

(a)

Recommend to drink $1.5 \mathrm{~L} /$ day of water, if the study subjects do not have chronic renal failure or chronic heart failure.

(b)

If the study subjects have chronic renal filhure or chronic heart failure, the attending physician will instruct on suitable volume of fluid intake according to the condition.

3 Symptoms that could be indicative of ketoacidosis

(a) measure plasma beta-hydroxybutyric acid

(b) Consult the attending physician if the plasma beta-hydroxybutyric acid is $\geq 600 \mu \mathrm{mol} / \mathrm{L}$

4 Symptoms that could be indicative of sick day

(a) consider ketoacidosis even if plasma glucose level is normal

(b) measure plasma beta-hydroxybutyric acid every 3-4 hours

(c) intake 30-60 g of carbohydrate and 200-500 $\mathrm{ml}$ of water

(d) inject bolus insulin

(e) avoid excess insulin reduction

(f) call ambulance if abdominal pain, nausea, vomiting, lassitude, respiratory distress, etc. are not improved

5 Criteria for dapagliflo zin withdrawal

(a) Consult the attending physician if physical deteriorationfillness or sick day

6 Symptoms that require at emergency consultation

symptoms including abdominal pain, nausea, vomiting, lassitude, respiratory distress, etc.

(a) are not improved even if plasma glucose, self-measured plasma beta-hydroxybutyric acid is within the normal range.

(b)

self-measured plasma beta-hydroxybutyric acid is $1,000 \mu \mathrm{mol} / \mathrm{L}$ or higher, and/or keto acidosis-related symptoms are not improved

(c) the study subjects brings card to indicate that they are patients with type 1 diabetes mellitus and are administrating SGL T2 inhibitor when receiving emergency consultation

A pre-observation period of 4 weeks was established before the intervention (administration of $5 \mathrm{mg}$ dapagliflozin). During this period, fasting plasma beta-hydroxybutyric acid (BOHB), flash glucose monitoring (FGM), and self-monitoring of blood glucose (SMBG) were measured and recorded. The start of dapagliflozin administration was set as day 0 of the observation period. The study subjects visited the research institutions four times; at weeks $-4,0,2$, and 4 . The study subjects were issued a digital camera and instructed to take a picture of each meal they ate throughout the observation period.

[Group A] Study subjects who reduced bolus insulin dose by $10 \%$

Subjects whose basal/TDD ratio was $<0.4$ were instructed not to reduce the basal insulin dose but to reduce the bolus insulin dose by $10 \%$. The $10 \%$ reduction of the bolus insulin dose was based on a $90 \%$ carbohydrate insulin ratio (CIR) and was rounded to the nearest whole number in case of insulin therapy with multiple daily injections (MDI); alternatively, it was rounded down to two decimal places in case of continuous subcutaneous insulin infusion (CSII). The study subjects were instructed to follow this instruction for 3 days from the start of the intervention. After the fourth day, subjects were able to titrate both basal and bolus doses according to the "Algorithm for Basal Insulin Titration after SGLT2 
Administration (Figure 2)" and "Algorithm for Bolus Insulin Titration after SGLT2 Administration (Figure 3)."

[Group B] Study subjects who reduced basal insulin by $10 \%$

Study subjects whose basal/TDD was $\geq 0.4$ were instructed to reduce their total insulin dose by $10 \%$, reducing the basal insulin dose only. The dose of basal insulin was rounded down to one decimal place in case of MDI or to two decimal places in case of CSII. The study subjects were instructed to follow this instruction for 3 days from the start of the intervention. After the fourth day, subjects were able to titrate both basal and bolus doses according to the "Algorithm for Basal Insulin Titration after SGLT2 Administration (Figure 2)" and "Algorithm for Bolus Insulin Titration after SGLT2 Administration (Figure 3)."

\section{Eligibility criteria}

In line with the objectives of the study and to ensure the safety of the subjects, the inclusion and exclusion criteria explained in Table 2 were established. To appropriately evaluate the efficacy of the study drugs, patients requiring a legal representative were excluded.

\section{Table 2. Inclusion and Exclusion Criteria}

\section{Inclusion Criteria}

Patients who meet all of the following criteria may be eligible to be included in this study:

1 Outpatient in the research institutions included in this study, who are diagnosed with type 1 diabetes mellitus before 6 months or more of giving their consent

2 Patients who have conducted intensive insulin therapy for 1 year or longer

3 Patients who are well-educated in carbohydrate counting, and who can conduct insulin self-titration

4 Patients with good understanding of the disease and capability to recognize DKA (symptoms and use of ketone meter)

5 Male and female aged $\geq 20$ years and $<80$ years when giving their consent

6 Patients who provide their consent in a written form

Rationale for the inclusion criteria:

1-3: for the appropriate evaluation of the efficacy outcomes in the RISING-STAR study.

4: for the safety of the study subjects in the real-world situation.

5: for the participation of the study subjects by their free will.

\section{Exclusion Criteria}


Patients who fall into any of the following criteria are excluded from participating in the study:

1 Patients who use SGLT2 inhibitor at the time of consent

2 Patients whose eGFR is less than $45 \mathrm{ml} / \mathrm{min} / 1.73 \mathrm{~m} 2$

3 Patients whose activities of daily living (ADL) are PS2 or higher

4 Patients with dementia or cognitive impairment

5 Patients whose BMI is less than $18.5 \mathrm{~kg} / \mathrm{m} 2$

6 Patients with a history of ketoacidosis within 3 months before giving their consent

7 Patients with a history of cardiovascular disease (myocardial infarction, heart failure, and angina) within 3 months before giving their consent

8 Patients whose $\mathrm{HbAl} \mathrm{c}$ is $10.5 \%$ or higher

9 Patients who had hypoglycemia $\geq 14$ times within 4 weeks of giving their consent Patients with anemia (male: $\mathrm{Hb}$ is $13 \mathrm{~g} / \mathrm{dL}$ or less, female: $\mathrm{Hb}$ is $12 \mathrm{~g} / \mathrm{dL}$ or less), hypoalbuminemia (serum albumin is $3.5 \mathrm{~g} / \mathrm{dL}$ or less), or nephrotic syndrome (urinary protein is $3.5 \mathrm{~g} /$ day or more, and serum albumin is $\leq 3.0 \mathrm{~g} / \mathrm{dL}$ ) caused by primary diseases other than diabetic nephropathy

11

Patients who are breastfeeding, pregnant, possibly pregnant, or planning to be pregnant

Patients with neoplasms. A patient who has just undergone chemotherapy and has

12 some early signs of being in remission are be enrolled. However, those who have completed treatment and/or show no relapse can be considered to be participants of this study

13 Patients who have contraindications to using the drug used in the study

14 Patients who have diet therapy with carbohydrate of less than $40 \%$ of total calories

15 Patients with poor adherence as judged by the investigators

16

Patients with other conditions that the responsible investigator/sub-investigator consider inappropriate to allow participation in the study

\section{Observations}

Observations and the schedule are shown in Tables 3 and 4. In principle, the study subjects visited the research institutions, and at every visit, blood tests (fasting) and urine tests (spot) were performed. Investigators collected and entered the examination results listed in Table 3 in the case report form (CRF) and sent the CRF to the Data Center. Adverse events were followed as safety endpoints throughout the study. The items that the study subjects measured by themselves were recorded on specific documents and sent to the Data Center via the investigators. No changes to pilot trial assessments or measurements after pilot trial commencement, including eligibility criteria, have been planned.

\section{Table 3. Observation items}

1. Eligibility information 


\begin{tabular}{|l|l|}
\hline $\begin{array}{l}\text { Observation } \\
\text { point }\end{array}$ & At consenting, enrollment \\
\hline $\begin{array}{l}\text { Observation } \\
\text { item }\end{array}$ & $\begin{array}{l}\text { sex, age/date of birth, inclusion criteria, exclusion criteria, date of giving } \\
\text { consent, total daily insulin dose (TDD), basal insulin dose (Basal), bolus insulin } \\
\text { dose, HbA1c }\end{array}$ \\
\hline
\end{tabular}

\section{Background information}

\begin{tabular}{|l|l|}
\hline $\begin{array}{l}\text { Observation } \\
\text { point }\end{array}$ & week -4 \\
\hline $\begin{array}{l}\text { Observation } \\
\text { item }\end{array}$ & $\begin{array}{l}\text { height, age, gender, presence/absence of smoking habit, presence/absence of } \\
\text { drinking habit, wakeup time, bedtime, comorbidity (presence/absence or } \\
\text { history of macrovascular/microvascular disease, dyslipidemia, hypertension, } \\
\text { hepatic disease), information regarding kinds of medication* (medicine for } \\
\text { hypertension, dyslipidemia, or diabetes mellitus), type and dose of insulin, } \\
\text { allergy }\end{array}$ \\
\hline
\end{tabular}

* obtained by calculation

3. Physical examination

\begin{tabular}{|l|l|}
\hline $\begin{array}{l}\text { Observation } \\
\text { point }\end{array}$ & week -4, week 0, week 2 (optional), week 4 \\
\hline $\begin{array}{l}\text { Observation } \\
\text { item }\end{array}$ & $\begin{array}{l}\text { body temperature, blood pressure (sitting position, office blood pressure), } \\
\text { pulse rate, body weight, body mass index*, body composition (skeletal muscle } \\
\text { mass, body fat mass) }\end{array}$ \\
\hline
\end{tabular}

* obtained by calculation

4. Medication information (except study agent and insulin)

\begin{tabular}{|l|l|}
\hline Observation point & week -4 , week 0, week 2 (optional), week 4 \\
\hline Observation item & presence/absence and content of change in type or dose of medication \\
\hline
\end{tabular}

5. Medication information (study agent, insulin) 


\begin{tabular}{|l|l|}
\hline Observation point & throughout observation period \\
\hline Observation item & $\begin{array}{l}\text { presence/absence of medication of study agent } \\
\text { type and dose of insulin } \\
\end{array}$ \\
& $*$ study subjects self-record in a diary \\
\hline
\end{tabular}

6. Blood tests (fasting)

\begin{tabular}{|l|l|}
\hline $\begin{array}{l}\text { Observation } \\
\text { point }\end{array}$ & week -4, week 0, week 2 (optional), week 4 \\
\hline $\begin{array}{l}\text { Observation } \\
\text { item }\end{array}$ & $\begin{array}{l}\text { red blood cell count, white blood cell count, hemoglobin, hematocrit, blood } \\
\text { platelet count, hepatic enzymes (aspartate aminotransferase, alanine } \\
\text { aminotransferase, lactose dehydrogenase, alkaline phosphatase, gamma- } \\
\text { glutamyl transferase, urinalysis, total cholesterol, high-density lipoprotein, } \\
\text { low-density lipoprotein, triglycerides, blood urea nitrogen, creatinine (Cre), } \\
\text { estimated glomerular filtration rate, HbA1c (or glycoalbumin), plasma glucose, } \\
\text { serum albumin (Alb) }\end{array}$ \\
\hline $\begin{array}{l}\text { Observation } \\
\text { point }\end{array}$ & $\begin{array}{l}\text { week 0, week 4 } \\
\text { Observation }\end{array}$ \\
\hline
\end{tabular}

7. Urine tests (spot)

\begin{tabular}{|l|l|}
\hline $\begin{array}{l}\text { Observation } \\
\text { point }\end{array}$ & week -4, week 0, week 2 (optional), week 4 \\
\hline $\begin{array}{l}\text { Observation } \\
\text { item }\end{array}$ & $\begin{array}{l}\text { specific gravity, pH, protein, glucose, ketone body, occult blood, urobilinogen, } \\
\text { bilirubin, u-mAlb, U-Cre, U-mAlb/Cre ratio }\end{array}$ \\
\hline
\end{tabular}

8. Special blood tests (fasting, using residual sample of "6. Blood tests")

\begin{tabular}{|l|l|}
\hline $\begin{array}{l}\text { Observation } \\
\text { point }\end{array}$ & week 0, week 4 \\
\hline $\begin{array}{l}\text { Observation } \\
\text { item }\end{array}$ & $\begin{array}{l}\text { total ketone body, beta-hydroxybutyric acid, acetoacetic acid, plasma } \\
\text { microRNA }\end{array}$ \\
\hline
\end{tabular}

9. Ultrasound cardiography (UCG) 


\begin{tabular}{|l|l|}
\hline $\begin{array}{l}\text { Observation } \\
\text { point }\end{array}$ & week -4 , week 4 \\
\hline $\begin{array}{l}\text { Observation } \\
\text { item }\end{array}$ & $\begin{array}{l}\text { ultrasound cardiography (early diastolic filling velocity, atrial filling velocity, } \\
\text { E/A, e' }, \text { E/e', DT, IVRT, TR, LVEF, LVEDV, LVESV, LAVI, LVDd, LVDs) }\end{array}$ \\
\hline
\end{tabular}

10. Quality-of-life score (questionnaire to whom the study subjects directly answer)

\begin{tabular}{|l|l|}
\hline $\begin{array}{l}\text { Observation } \\
\text { point }\end{array}$ & week -4, week 0, week 4 \\
\hline $\begin{array}{l}\text { Observation } \\
\text { item }\end{array}$ & $\begin{array}{l}\text { DTSQs (The Diabetes Treatment Satisfaction Questionnaire, status version) } \\
\text { used measures treatment satisfaction specific to diabetes mellitus, widely }\end{array}$ \\
\hline
\end{tabular}

11. Other items the study subjects measure by themselves 1 


\begin{tabular}{|l|l|}
\hline Observation & $\begin{array}{l}\text { throughout week -4 to week 0, week 0 to week } 4 \\
\text { ptudy subjects will use the Freestyle Libre (Abbott Japan) for flash glucose } \\
\text { monitoring (FGM) after receiving full explanation of how to use it. Since the } \\
\text { sensor of the Freestyle Libre can be used for } 2 \text { weeks (14 days), investigators } \\
\text { will give } 2 \text { sensors to each study subject in advance of each period. Study } \\
\text { subjects will change and install a sensor every } 2 \text { weeks. } \\
\text { The data which the study subjects measure by themselves are recorded in the } \\
\text { study subjects' diaries. }\end{array}$ \\
\hline item & $\begin{array}{l}\text { Study subjects will measure ketone bodies once daily before breakfast at home } \\
\text { using the Freestyle Libre. Study subjects will also measure ketone bodies at } \\
\text { will at physical deconditioning, sick days, or onset of symptoms suggesting } \\
\text { ketoacidosis. } \\
\text { 1. Plasma glucose (FGM) } \\
\text { Study subjects will measure plasma glucose continuously at home using the } \\
\text { Freestyle Libre. } \\
1 . \text { Plasma glucose (self-monitoring of blood glucose; SMBG) } \\
\text { Study subjects will conduct SMBG } 4 \text { times per day (before breakfast, before } \\
\text { lunch, before dinner, and before bedtime) and upon the awareness of } \\
\text { hypoglycemic symptoms or at FGM values of less than } 70 \text { mg/dL at home using } \\
\text { the Freestyle Libre. } \\
\text { 1. Dose of insulin } \\
\text { 2. Awareness of hypoglycemia }\end{array}$ \\
\hline
\end{tabular}

12. Other items the study subjects measure by themselves 2 


\begin{tabular}{|c|c|}
\hline $\begin{array}{l}\text { Observation } \\
\text { point }\end{array}$ & throughout observation period \\
\hline $\begin{array}{l}\text { Observation } \\
\text { item }\end{array}$ & $\begin{array}{l}\text { 1. diet and relevant information } \\
\text { Study subjects will record their diet and relevant information every day } \\
\text { throughout the observation period using software. } \\
\text { 1. gender, age, height, target body weight, activities of daily life: prespecified } \\
\text { value (enter once) } \\
\text { 2. body weight, percent body fat, body water, alcohol intake, confectionery } \\
\text { intake, staple food intake, main dish intake, side dish intake, milk product } \\
\text { intake, fruit intake, number of steps (every day) } \\
\text { 3. energy, protein, lipid, carbohydrate, dietary fiber, sugar (every meal) }\end{array}$ \\
\hline $\begin{array}{l}\text { Obse } \\
\text { item }\end{array}$ & $\begin{array}{l}\text { 1. Fasting plasma beta-hydroxybutyric acid (ketone body) } \\
\text { Study subjects will measure ketone bodies once daily before breakfast at home } \\
\text { using the Freestyle Libre. Study subjects will also measure ketone bodies at } \\
\text { will at physical deconditioning, sick days, or onset of symptoms suggesting } \\
\text { ketoacidosis. } \\
\text { 1. Plasma glucose (FGM) } \\
\text { Study subjects will measure plasma glucose continuously at home using the } \\
\text { Freestyle Libre. } \\
\text { 1. Plasma glucose (SMBG) } \\
\text { Study subjects will conduct SMBG } 4 \text { times per day (before breakfast, before } \\
\text { lunch, before dinner, and before bedtime) and upon awareness of } \\
\text { hypoglycemic symptoms or at FGM values of less than } 70 \mathrm{mg} / \mathrm{dL} \text { at home using } \\
\text { the Freestyle Libre. } \\
\text { 1. Dose of insulin } \\
\text { 2. Awareness of hypoglycemia }\end{array}$ \\
\hline
\end{tabular}

13. Adverse events and diseases or the like 


\begin{tabular}{|l|l|}
\hline $\begin{array}{l}\text { Observation } \\
\text { point }\end{array}$ & throughout observation period \\
\hline item & $\begin{array}{l}\text { Cbservation } \\
\text { Adsease or the like. } \\
\text { Adverse events and diseases or the like are observed throughout the study. } \\
\text { Adverse events and diseases or the like include medication side-effects and } \\
\text { clinically significant abnormal fluctuations in test results. Investigators will } \\
\text { collect information on the presence/absence of hypoglycemia, hypoglycemia, } \\
\text { and other adverse events and diseases or the like by interview at every } \\
\text { observation point. Any occurrence of adverse events and diseases or the like } \\
\text { are recorded into the case report form. Study subjects will be further followed } \\
\text { up with if necessary. } \\
\text { *The classification of adverse events and disease or the like is based on } \\
\text { MedDRA/J. } \\
\text { Refer "10. Safety evaluation analysis" }\end{array}$ \\
\hline
\end{tabular}

\section{Data management and monitoring}

Written informed consent was obtained from all participants. Linkable anonymization using the central registration number was used to identify subjects. Data collection and management were carried out by third-party entities to avoid bias. Data management was be performed by Soiken Inc. (Data Center). The Data Center prepared a procedure manual for data management. The Data Center's approval was required prior to sending any data related to the subjects in an electronic format. If data were transmitted over an unsecured electronic network, the data were encoded at the source. The investigators were responsible for appropriate storage of the correspondence table prepared by them to identify the subjects, in accordance with the procedures at the particular research institution. This correspondence table will be retained for 5 years after the completion of the RISING-STAR study. Appropriate measures, such as encoding or deletion, will be taken to ensure that the subjects cannot be identified, in accordance with applicable laws and regulations.

The Data Center will monitor the RISING-STAR study to manage and ensure quality. The monitoring manager will monitor subjects in accordance with the prescribed manual on monitoring. For data quality management, the principal investigator and central committee will confirm the progress of the RISINGSTAR study as necessary through the Data Center to ensure conformance with the protocol and the Ethical Guidelines for Medical and Health Research Involving Human Subjects (February 28, 2017; Ministry of Education, Culture, Sports, Science and Technology/Ministry of Health, Labor and Welfare) 
and the Clinical Trials Act (April 14, 2017; Ministry of Education, Culture, Sports, Science and Technology/Ministry of Health, Labor and Welfare).

\section{Primary endpoints}

The frequency of hypoglycemic episodes per day was confirmed using SMBG during the intervention period (administration of $5 \mathrm{mg}$ dapagliflozin).

\section{Secondary endpoints}

1. Frequency of ketosis before and after the intervention

Ketosis was defined as plasma $B O H B \geq 600 \mu \mathrm{mol} / \mathrm{L}$ [27-28]. The frequency of ketosis was defined as the proportion of the number of days in which ketosis occurs in the study subjects during the pre-observation period and the observation period after the intervention.

2. Frequency of hypoglycemic episodes per day before and after the intervention detected by FGM

3. Change and difference in change between intervention groups on the following items, before and after the intervention

3-1. Fasting plasma beta-hydroxybutyric acid (ketone body)

3-2. Basal insulin dose*, bolus insulin dose*, total insulin dose*, CIR, and insulin sensitivity factor (ISF)

3-3. Time spent in hypoglycemia (percentage of time spent in glucose range $\leq 70 \mathrm{mg} / \mathrm{dL}$ ), time spent in hyperglycemia (percentage of time spent in glucose range $\geq 70 \mathrm{mg} / \mathrm{dL}$ ), and time spent in nocturnal hypoglycemia, detected using FGM

3-4. Vital signs: blood pressure, pulse rate

3-5. BMI, skeletal muscle masst, fat mass $†$

3-6. Blood biomarkers: red blood cell count, white blood cell count, hemoglobin, hematocrit, blood platelet count, hepatic enzymes (aspartate aminotransferase (AST), alanine aminotransferase (ALT), lactose dehydrogenase (LDH), alkaline phosphatase (ALP), gamma-glutamyl transferase), urinalysis, total cholesterol (T-Chol), high-density lipoprotein, low-density lipoprotein, triglycerides (TG), blood urea nitrogen, creatinine (Cre), estimated glomerular filtration rate (eGFR), brain natriuretic peptide (BNP)十, $\mathrm{HbA1c}$ (or glycoalbumin), plasma glucose, albumin, C-reactive protein (CRP)†, and CRP index $\dagger$

3-7. Urine biomarkers: specific gravity, $\mathrm{pH}$, protein, glucose, ketone body, occult blood, urobilinogen, bilirubin, microalbumin, creatinine, and microalbumin-creatinine ratio

3-8. Total ketone bodiest, beta-hydroxybutyric acidt, and acetoacetic acid $\dagger$

3-9. Quality-of-life score (DTSQ) 
* Measured by daily dose, + measured at visits 2 and 4 only

\section{Safety endpoints}

Frequency of adverse events (including frequency of hypoglycemic episodes detected by FGM).

\section{Exploratory endpoints}

Correlation between changes in dietary habits, dietary content, and nutrient intake and changes in fasting plasma $\beta$-hydroxybutyric acid levels.

Change in plasma microRNA profile.

Change in cardiac function estimated by ultrasonic echocardiography (UCG).

\section{Rationale underlying the sample size}

The RISING-STAR study was designed as an exploratory study, and no prior studies have reported the frequency of hypoglycemia after the administration of SGLT2 inhibitors. We hypothesized that the frequency of hypoglycemic episodes per day would increase after the administration of an SGLT2 inhibitor if the dose of basal insulin was not titrated. The baseline frequency of hypoglycemia was set as $7 \pm 6$ times/month when insulin glargine was used in patients with type 1 diabetes [29]. The minimum sample size required to achieve a significance of 0.05 for a one-sided t-test with a statistical power of $80 \%$ was determined. When the sample size was 26 patients in one group, the percent increase in hypoglycemia was more than $60 \%$, and the sample size was estimated to be sufficient. With an estimated dropout rate of $10 \%$, the planned number of subjects (60 subjects, 30 in each group) was thought to have enough statistical power for an increased hypoglycemic frequency of more than $60 \%(11.2 \pm 6$ times/month) in Group A (Basal/TDD $<0.4$, the study subjects were instructed to not reduce basal insulin dose but instructed to reduce bolus insulin dose by 10\%) from $7 \pm 6$ times/month in Group B (Basal/TDD $\geq 0.4$, the study subjects were instructed to reduce basal insulin by $10 \%$ ).

The RISING-STAR study will be conducted at seven research institutions, where a total of 350 patients with type 1 diabetes are being treated. From a previous survey, $30 \%$ of these patients were eligible for SGLT2 inhibitors as per the Japanese indications, meaning that approximately 100 patients could use an SGLT2 inhibitor with insulin. Among the 100 patients, all patients who sign a written consent form will be enrolled in the study and stratified into Group $A$ (Basal/TDD $<0.4$, subjects instructed to not reduce basal insulin dose but reduce bolus insulin dose by $10 \%$ ) or Group B (Basal/TDD $>0.4$, subjects instructed to reduce basal insulin by $10 \%$ ). The proportion of patients who will consent is assumed to be $80 \%$, and the proportion of patients who meet the inclusion criteria and none of the exclusion criteria is assumed to be $80 \%$. Under these conditions, the target number of 60 study subjects is feasible.

\section{Analysis of the primary endpoint}


Summary statistics will be calculated for the number of hypoglycemic events per day (plasma glucose level defined by $S M B G \leq 70 \mathrm{mg} / \mathrm{dL}$ ) during the intervention period (from baseline to week 4) using the full analysis set (FAS) as the main analysis set and the per protocol set for the sensibility analysis set. For comparisons between groups, a two-sample t-test and analysis of covariance will be conducted, and differences between the groups and their $95 \%$ confidence intervals will be calculated. HbA1c, age, and frequency of hypoglycemia ( $\leq 70 \mathrm{mg} / \mathrm{dL}$, confirmed by SMBG) per day during the pre-observation period before the intervention (week -4 to baseline) will be used as covariates in the analysis of covariance. If the data is not normally distributed, the summary statistics will be calculated after logarithmic transformation.

\section{Analysis of the secondary endpoints}

For the analysis of secondary endpoints 1 (frequency of ketosis) and 2 (frequency of hypoglycemia detected by FGM), summary statistics of measurements and changes will be calculated using the FAS during the pre-observation period before the intervention (week - 4 to baseline), and the observation period after the intervention (baseline to week 4) in each group. For the measurements, a two-sample t-test will be used for comparisons between groups, and for the change, a one-sample t-test will be used for comparison in each group. If the data are not normally distributed, the summary statistics will be calculated after logarithmic transformation.

For the analysis of secondary endpoint 3 , summary statistics will be calculated using the FAS for measurements at each observation point and change in the measurements from baseline to each observation point after the intervention. For the measurement, a two-sample t-test will be used for comparisons between groups, and for the change in the measurement, a one-sample t-test will be used for comparison in each group.

\section{Analysis of the safety endpoints}

For the analysis of the safety endpoints, a table of all adverse events and diseases or the like will be created for each group using the safety analysis set, and comparisons will be performed between groups as necessary using Fisher's exact test.

\section{Analysis of exploratory endpoints}

For the analysis or correlation between changes in dietary habits, dietary content, nutrient intake, and changes in fasting plasma BOHB acid, the Spearman rank correlation coefficient and its $95 \%$ confidence interval will be calculated and evaluated for significance. The subjects will be instructed to take pictures of each of their meals using a digital camera. The stored images will be uploaded to a data cloud, and diabetologists will analyze the images according to the Standard Tables of Food Composition in Japan using a specialized application (Asken, Wit Co.; Orange, CA). The volumes and calories of carbohydrates, proteins, fats, and nutrient intakes will be calculated by the system and referred to as "online nutritional evaluation." 


\section{Ethics}

The protocol was approved by the Kyoto Prefectural University of Medicine Clinical Research Review Board (CRB5180001) and registered at jRCT (jRCTs051190114).

Table 4. Observation schedule

\begin{tabular}{|c|c|c|c|c|c|c|}
\hline \multirow[t]{2}{*}{ observation item } & & \multicolumn{5}{|c|}{ observation period / observation point } \\
\hline & enrollment & $\begin{array}{l}\text { week } \\
\square 4 *\end{array}$ & $\begin{array}{l}\text { baseline } \\
\text { week } 0 *\end{array}$ & $\begin{array}{c}\text { week } \\
2 \\
\pm 1 \\
\text { week }\end{array}$ & $\begin{array}{c}\text { week } \\
4 \\
\pm 1 \\
\text { week }\end{array}$ & $\begin{array}{c}\text { at } \\
\text { discontinuation }\end{array}$ \\
\hline obtaining consent & ○ & & & & & \\
\hline 口Eligibility information & ○ & & & & & \\
\hline 口Background information & $\bullet$ & ○ & & & & \\
\hline 口Physical examination & & ○ & ○ & $\triangle$ & ○ & $\triangle$ \\
\hline $\begin{array}{l}\text { Medication } \text { information } \\
\text { (except study agent and } \\
\text { insulin) }\end{array}$ & & ○ & ○ & $\triangle$ & ○ & $\triangle$ \\
\hline $\begin{array}{l}\square \text { Medication information (study } \\
\text { agent, insulin) }\end{array}$ & & & & & & \\
\hline aBlood tests & & $\bullet$ & $\bullet$ & $\triangle$ & $\bullet$ & $\triangle$ \\
\hline पUrine tests & & $\bullet$ & $\bullet$ & $\triangle$ & $\bullet$ & $\triangle$ \\
\hline ¿Special blood tests & & $\boldsymbol{\Delta}$ & $\boldsymbol{\Delta}$ & & $\boldsymbol{\Delta}$ & $\boldsymbol{\Delta}$ \\
\hline पUCG & & ○ & & & $\bullet$ & $\triangle$ \\
\hline ¿QOL score & & $\bullet$ & $\bullet$ & & 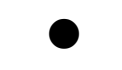 & \\
\hline $\begin{array}{l}\text { Other items the study } \\
\text { subjects measure } \\
\text { themselves } 1\end{array}$ & & & days & 28 & & \\
\hline $\begin{array}{l}\text { Other items the study } \\
\text { subjects measure by } \\
\text { themselves } 2\end{array}$ & & & & & & \\
\hline $\begin{array}{l}\text { पAdverse events and diseases } \\
\text { or the like }\end{array}$ & & & & & & \\
\hline
\end{tabular}




\section{-required}

$\triangle$ optional

$\Delta$ conduct if a residual sample exists

* Conducted before the start of the study agent administration

UCG, ultrasound cardiography; QOL, quality of life.

\section{Discussion}

The findings from this study will provide knowledge about the reduction of the basal insulin dose combined with an SGLT2 inhibitor in patients with type 1 diabetes, which may reduce the frequency of hypoglycemia associated with combination therapy. The results will be disseminated through presentations at appropriate conferences and meetings as well as through publications in peer-reviewed journals.

While conducting this pilot study, we assumed that given sufficient basal insulin doses, hypoglycemia would be more frequent in patients with type 1 diabetes when combined with SGLT2 inhibitors if basal insulin doses are not reduced. The best study design to clarify this question is to observe hypoglycemic attacks as the primary endpoint in type 1 diabetes with SGLT2 inhibitors or placebo. In this study, the best study design would be to stratify participants according to the ratio of basal insulin to total insulin and to determine the association between the ratio of basal insulin to total insulin and hypoglycemic attacks. However, we assume from previous reports that a $10 \%$ reduction in total insulin dose is necessary to avoid hypoglycemia with SGLT2 inhibitor treatment $[12,15,16]$.

SGLT2 inhibitor treatment in patients with type 1 diabetes mellitus has been reported to improve glycemic control [12]. The amount of additional insulin was determined from carbohydrate and pre-prandial blood glucose intake and treatment target blood glucose levels by applied carbo-counting in patients with type 1 diabetes covered in this pilot study. We envisioned avoiding hypoglycemia during SGLT2 inhibitor therapy by reducing either the basal insulin dose, the insulin effect value, or both. After adhering to their doctor's insulin reduction instructions for 3 days, patients will be allowed to adjust their own insulin dose appropriately by watching their blood glucose levels over those 3 days. Subjects will be divided into two groups: those that undergo a $10 \%$ reduction in basal insulin dose or a $10 \%$ reduction in insulin effect dose. In addition, the division between the two groups will not be randomized but rather will refer to insulin levels prior to SGLT2 inhibitor treatment, with a $10 \%$ reduction in basal insulin levels in patients with basal insulin levels greater than $40 \%$ of total insulin, and a $10 \%$ reduction in insulin effect size in patients with basal insulin levels less than $40 \%$ of total insulin, to reduce the dose by $10 \%$. We assume that the risk of developing hypoglycemia will increase in the group without insulin reduction, and we did not establish a group that did not indicate insulin reduction. 
We assume that when insulin therapy is combined with an SGLT2 inhibitor for patients with type 1 diabetes mellitus, the frequency of hypoglycemia will increase if the basal insulin dose is not reduced, provided there is an adequate basal insulin dose. In cases where the basal insulin dose is less than $40 \%$ of the total insulin dose, it is possible that an inadequate basal insulin dose will not have been administered and that the amount of additional insulin would have been excessive. The cause of the overdose of additional insulin may be because the amount of carbohydrates ingested would have been excessive and that the insulin effect value would have been estimated to be higher than the true value. To account for these possibilities, in cases where basal insulin levels are less than $40 \%$ of total insulin, we have not indicated a reduction in basal insulin levels, but rather a $10 \%$ reduction in insulin effect values.

The purpose of this pilot study is to analyze the feasibility of future randomized trials. The first randomized trial is envisioned as a two-arm randomized trial in which a reduction in basal insulin dose is indicated or no reduction in basal insulin dose is instructed for concomitant use of SGLT2 inhibitors in patients with type 1 diabetes to prevent the development of hypoglycemia. To conduct this randomized trial, we need to determine the risk of diabetic ketoacidosis with SGLT2 inhibitor treatment in type 1 diabetes. SGLT2 inhibitor treatment in type 1 diabetes may increase the risk of diabetic ketoacidosis 6fold $(20,30)$. The U.S. Food and Drug Administration estimates that one additional case of ketoacidosis occurs every 26 years when patients with type 1 diabetes are treated with sotagliflozin. Assuming a case fatality rate of $0-4 \%$, this estimate corresponds to 16 additional deaths per year per 100,000 patients with type 1 diabetes treated $(31,32)$. Thus, although a reduction in basal insulin dose in SGLT2 inhibitor therapy in type 1 diabetes is beneficial in the prevention of hypoglycemia, there is a risk of increasing the risk of diabetic ketoacidosis [17]. In this pilot study, prevention of hypoglycemic attacks was the primary endpoint, with home self-performed ketone measurements as a secondary endpoint, which will provide insight into the increase in ketones when a reduction in basal insulin dose is indicated. This will be essential for the design of future randomized trials.

The first clinical question is whether reducing the basal insulin dose to prevent the development of hypoglycemia is a risk of diabetic ketoacidosis in SGLT2 inhibitor therapy in type 1 diabetes. Does SGLT2 inhibitor treatment increase the risk of diabetic ketoacidosis in type 1 diabetes without reducing basal insulin levels? To clarify the purpose of this study, the frequency of ketosis may also be used as a primary endpoint of this pilot study. However, in this pilot study, for safety reasons, the attending physician will intervene if the self-performed ketone body measurement is greater than $600 \mu \mathrm{M}$. This will allow the attending physician to intervene when ketones are increased and thus help to prevent ketoacidosis. Therefore, it is not possible to measure the frequency of the onset of ketosis in the absence of bias. Therefore, the frequency of onset of ketosis is not the primary endpoint.

A second future randomized trial, with the development of ketoacidosis as the primary endpoint, will compare the basal insulin dose reduction of up to $10 \%$ in this trial to the basal insulin dose reduction of up to $10 \%$ in this trial with a basal insulin dose reduction of more than $10 \%$ in this trial for patients with type 1 diabetes, assuming that ketoacidosis does develop. It is also important to know whether ketoacidosis occurs in this study when the basal insulin dose is reduced by up to $10 \%$. 


\section{Trial Status}

The RISING-STAR study started on March 2, 2020 with protocol version 1.1. The recruitment was completed on August 31, 2020.

\section{Declarations}

\section{Ethics approval and consent to participate}

The RISING-STAR study was registered with the Japan Registry of Clinical Trials (jRCTs051190114) and has been approved by the ethics committees of the Kyoto Prefectural University of Medicine (CRB5180001). The RISING-STAR study is to be conducted according to the Declaration of Helsinki. Written informed consent will be obtained from all the participants.

\section{Consent for publication}

Not applicable

\section{Funding}

The RISING-STAR study, including the article processing charge, is funded by AstraZeneca K.K. and Ono Pharmaceutical Co., Ltd. No drugs will be donated or funded by the sponsor. The funding bodies had no role in study design, data collection and analysis, decision to publish, or preparation of the manuscript.

\section{Competing interests}

M. H. reports grants from Asahi Kasei Pharma, Nippon Boehringer Ingelheim Co. Ltd., Mitsubishi Tanabe Pharma Corp., Daiichi Sankyo Co. Ltd., Sanofi K.K., Takeda Pharma Co. Ltd, Astellas Pharma Inc., Kyowa Kirin Co. Ltd., Sumitomo Dainippon Pharma Co. Ltd., Novo Nordisk Pharma Ltd., and Eli Lilly Japan K.K., outside the submitted work. M. A. reports personal fees from Novo Nordisk Pharma Ltd., Abbott Japan Co. Ltd., AstraZeneca plc, Kowa Pharma Co. Ltd., Ono Pharma Co. Ltd., Sumitomo Dainippon Pharma Co. Ltd., and Takeda Pharma Co. Ltd. outside the submitted work. M. Y. reports personal fees from MSD K.K., Sumitomo Dainippon Pharma Co. Ltd., Kowa Pharma Co. Ltd., AstraZeneca plc., Takeda Pharma Co. Ltd, Kyowa Kirin Co. Ltd., Daiichi Sankyo Co. Ltd., Kowa Pharma Co. Ltd., and Ono Pharma Co., Ltd. outside the submitted work.

Y. H. reports grant from Asahi Kasei Pharma and personal fees from Daiichi Sankyo Co. Ltd., Mitsubishi Tanabe Pharma Corp., Sanofi K.K., and Novo Nordisk Pharma Ltd., outside the submitted work.

M. F. received grants from Nippon Boehringer Ingelheim Co. Ltd., Kissei Pharma Co. Ltd., Mitsubishi Tanabe Pharma Corp, Daiichi Sankyo Co. Ltd., Sanofi K.K., Takeda Pharma Co. Ltd., Astellas Pharma Inc., MSD K.K., Kyowa Kirin Co., Ltd., Sumitomo Dainippon Pharma Co., Ltd., Kowa Pharma Co. Ltd., Novo Nordisk Pharma Ltd., Ono Pharma Co. Ltd., Sanwa Kagagu Kenkyusho CO., Ltd., Eli Lilly Japan K.K., 
Taisho Pharma Co., Ltd., Terumo Corp., Tejin Pharma Ltd., Nippon Chemiphar Co., Ltd., Abbott japan Co. Ltd., and Johnson \& Johnson k.k. Medical Co., and received honoraria from Nippon Boehringer Ingelheim Co., Ltd., Kissei Pharma Co., Ltd., Mitsubishi Tanabe Pharma Corp., Daiichi Sankyo Co. Ltd., Sanofi K.K., Takeda Pharma Co. Ltd., Astellas Pharma Inc., MSD K.K., Kyowa Kirin Co. Ltd., Sumitomo Dainippon Pharma Co. Ltd., Kowa Pharma Co. Ltd., Novo Nordisk Pharma Ltd., Ono Pharma Co. Ltd., Sanwa Kagaku Kenkyusho Co. Ltd., Eli Lilly Japan K.K., Taisho Pharma Co., Ltd., Bayer Yakuhin, Ltd., AstraZeneca K.K., Mochida Pharma Co. Ltd., Abbott japan Co. Ltd., Teijin Pharma Ltd., Arkray Inc., Medtronic Japan Co. Ltd., and Nipro Corp. outside the submitted work. The other authors have nothing to disclose.

\section{Availability of data and materials}

Data sharing is not applicable to this article as no datasets were generated or analyzed during the current study.

\section{Authors' contributions}

$\mathrm{MH}$ led the drafting of the manuscript. YH and MF reviewed the manuscript and study design and contributed to the final draft. The other authors will recruit participants and contributed to the final draft.

\section{Patient and Public Involvement statement}

Patients have not been involved in the design of the study, the selection of research questions, or outcome measurements. Participants will not be involved in the interpretation or the write-up of results. Participants will be given a simple summary of the study outcomes, written in Japanese, once the study has been completed.

Acknowledgments: We would like to thank Editage (www.editage.com) for English language editing. The authors thank all the clinical staff for their assistance with the execution of the clinical trial, and Soiken Inc. for their technical assistance in the launch and execution of this trial.

\section{References}

1. Ministry of Health, Labor and Welfare, Scientific Research Grant 2017, Study of type 1 diabetes mellitus to estimate actual condition, objective diagnostic criteria, and severity assessment based on daily activity and social activity (2018) Type 1 diabetes mellitus in which insulin secretion is completely lost. http://dmic.ncgm.go.jp/content/type1_insulin_20180817.pdf. Accessed 18 July 2019.

2. International Diabetic Federation. Diabetes Atlas Eighth Edition. 2017. https://www.idf.org/elibrary/epidemiology-research/diabetes-atlas.html. Accessed 18 July 2019.

3. Position Statement. 9. Pharmacologic Approaches to Glycemic Treatment: Standards of Medical Care in Diabetes-2019. American Diabetes Association. Diabetes Care 2019 Jan; 42(Supplement 1): S90-S102. 
4. Davidson PC, Hebblewhite HR, Steed RD, Bode BW. Analysis of guidelines for basal-bolus insulin dosing: basal insulin, correction factor, and carbohydrate-to-insulin ratio. Endocr Pract 2008;14:1095-1101pmid:19158048

5. Lebovitz H, Sherr J, Tamborlane W, Bode B. Insulin Pump Therapy in Therapy for Diabetes Mellitus and Related Disorders. 5th ed. Lebovitz H, Ed. Alexandria, VA, American Diabetes Association, 2009, p. 322-331

6. Wolpert H, Wolpert H. Smart Pumping for People with Diabetes. Wolpert H, Ed. Alexandria, VA, American Diabetes Association, 2002

7. Kuroda A, Kaneto H, Yasuda T, Matsuhisa M, Miyashita K, Fujiki N, Fujisawa K, Yamamoto T, Takahara M, Sakamoto F, T Matsuoka T, Shimomura I. Basal Insulin Requirement Is $\sim 30 \%$ of the Total Daily Insulin Dose in Type 1 Diabetic Patients Who Use the Insulin Pump. Diabetes Care 2011 May; 34(5): 1089-1090.

8. King AB. How much do I give? Reevaluation of insulin dosing estimation formulas using continuous glucose monitoring. Endocr Pract 2010;16:428-432

9. Purnell JQ, Brafett BH, Zinman B, Gubitosi-Klug RA, Sivitz W, Bantle JP et al. Impact of Excessive Weight Gain on Cardiovascular Outcomes in Type 1 Diabetes: Results From the Diabetes Control and Complications Trial/Epidemiology of Diabetes Interventions and Complications (DCCT/EDIC) Study. Diabetes Care 2017; 40: 1756-62.

10. Tascini G, Berioli MG, Cerquiglini L, Santi E, Mancini G, Rogari F, Toni G, Esposito S. Carbohydrate Counting in Children and Adolescents with Type 1 Diabetes. Nutrients. 2018; 10 : 109.

11. Japan Diabetes Clinical Data Management Study Group. http://jddm.jp/data/index-2017.html (2007). Accessed 18 July 2019.

12. Boeder S, Edelman SV. Sodium-glucose Co-Transporter Inhibitors as Adjunctive Treatment to Insulin in Type 1 Diabetes: A Review of Randomized Controlled Trials. Diabetes Obes Metab. 2019;21 Suppl 2(Suppl 2):62-77.

13. Henry RR, Thakkar P, Tong C, Polidori D, Alba M. Efficacy and safety of canagliflozin, a sodiumglucose cotransporter 2 inhibitor, as add-on to insulin in patients with type 1 diabetes. Diabetes Care 2015;38:2258-2265

14. Dandona P, Mathieu C, Phillip M, Hansen L, Griffen SC, Tschope D. et al. Efficacy and safety of dapagliflozin in patients with inadequately controlled type 1 diabetes (DEPICT-1): 24 week results from a multicenter, double-blind, phase 3, randomized controlled trial. Lancet Diabetes Endocrinol. 2017;5:864-76

15. Mathieu C, Dandona P, Gillard P, Senior P, Hasslacher C, Araki E, Lind M, Bain SC, Jabbour S, Arya N, Hansen L, Thorén F, Langkilde AM, on behalf of the DEPICT-2 Investigators. Efficacy and Safety of Dapagliflozin in Patients With Inadequately Controlled Type 1 Diabetes (the DEPICT-2 Study): 24Week Results From a Randomized Controlled Trial. Diabetes Care 2018 Sep; 41(9): 1938-1946.

16. Pieber TR, Famulla S, Eilbracht J, Cescutti J, Soleymanlou N, Johansen OE, Woerle HJ, Broedl UC, Kaspers S. Empagliflozin as adjunct to insulin in patients with type 1 diabetes: a 4-week, 
randomized, placebo-controlled trial (EASE-1). Diabetes Obes Metab. 2015 Oct; 17(10): 928-935.

17. Rosenstock J, Marquard J, Laffel LM, Neubacher D, Kaspers S, Cherney DZ, et al. Empagliflozin as Adjunctive to Insulin Therapy in Type 1 Diabetes: The EASE Trials. Diabetes Care. 2018;41(12):256069

18. Buse JB, et al. Sotagliflozin in combination with optimized insulin therapy in adults with type 1 diabetes: The North American inTandem1 Study. Diabetes Care 2018;41(9):1970-80.

19. Danne T, et al. HbA1c and hypoglycemia reductions at 24 and 52 weeks with sotagliflozin in combination with insulin in adults with type 1 diabetes: The European inTandem2 Study. Diabetes Care 2018;41(9):1981-90.

20. Taylor SI, Garg SK, et al. Effects of sotagliflozin added to insulin in patients with type 1 diabetes. $\mathrm{N}$ Engl J Med 2017;377(24):2337-48.

21. Blau JE, Rother KI, Beitelshees AL. SGLT2 inhibitors as adjunctive therapy for type 1 diabetes: balancing benefits and risks. Lancet diabetes Endocrinol 2019; 7:949-958.

22. Patoulias D, Imprialos K, Stavropoulos K, Athyros V, Doumas M. SGLT-2 inhibitors in type 1 diabetes mellitus: a comprehensive review of the literature. Curr Clin Pharmacol. 7 August 2018 [Epub ahead of print]. DOI: 10.2174/1574884713666180807150509

23. Nauck MA, Del Prato S, Meier JJ, Duran-Garcia S, Rohwedder K, ELze M, et al. Dapagliflozin Versus Glipizide as Add-on Therapy in Patients With Type 2 Diabetes Who Have Inadequate Glycemic Control With Metformin A randomized, 52-week, double-blind, active-controlled noninferiority trial. Diabetes Care. 2011;34:2015-22

24. Wanner C, Heerspink HJL, Zinman B, Inzucchi SE, Koitka-Weber A, Matheus M. et al. Empagliflozin and Kidney Function Decline in Patients with Type 2 Diabetes: A Slope Analysis from the EMPA-REG OUTCOME Trial. J Am Soc Nephrol. 2018; 29:2755-69

25. Lehecka KE, Renukuntla VS, Heptulla, RA. Insight Into Hypoglycemia in Pediatric Type 1 Diabetes Mellitus. Int J Pediatr Endocrinol. 2012;2012(1):19.

26. Kovatchev B, Cobelli C. Glucose Variability: Timing, Risk Analysis, and Relationship to Hypoglycemia in Diabetes. Diabetes Care. 2016;39(4):502-10.

27. Schade DS, Eaton RP. Metabolic and clinical significance of ketosis. Spec Top in Endocrinol Metab. 1982;4:1-27

28. Wiggam MI, O’Kane MJ, Harper R, Atkinson AB, Hadden DR, Trimble ER, et al. Treatment of diabetic ketoacidosis using normalization of blood 3-hydroxybutyrate concentration as the endpoint of emergency management. A randomized controlled study. Diabetes Care. 1997;20(9):1347-52

29. Urakami T, Kuwabara R, Habu M, Okuno M, Suzuki J, Takahashi S. Efficacy and safety of switching to insulin glulisine from other rapid-acting insulin analogs in children with type 1 diabetes. J Diabetes Investig. 2015;6(1):87-90

30. Musso G, Roberto Gambino R, Cassader M, Paschetta E. Efficacy and safety of dual SGLT 1/2 inhibitor sotagliflozin in type 1 diabetes: meta-analysis of randomised controlled trials. BMJ 2019; 365

Page 24/28 
31. Hampp C, SwainRS, Horgan C, Dee E, Qiang Y, Dutcher SK, Petrone A, Tilney RC, Maro JC, Catherine A. Panozzo CA. Use of Sodium-Glucose Cotransporter 2 Inhibitors in Patients With Type 1 Diabetes and Rates of Diabetic Ketoacidosis. Diabetes Care 2020 Jan; 43(1): 90-97.

32. Benoit SR, Zhang Y, Geiss LS, Gregg EW, Albright A. Trends in Diabetic Ketoacidosis Hospitalizations and In-Hospital Mortality - United States, 2000-2014. Centers for Disease Control and Prevention. March 30, 2018 / 67(12);362-365

\section{Figures}

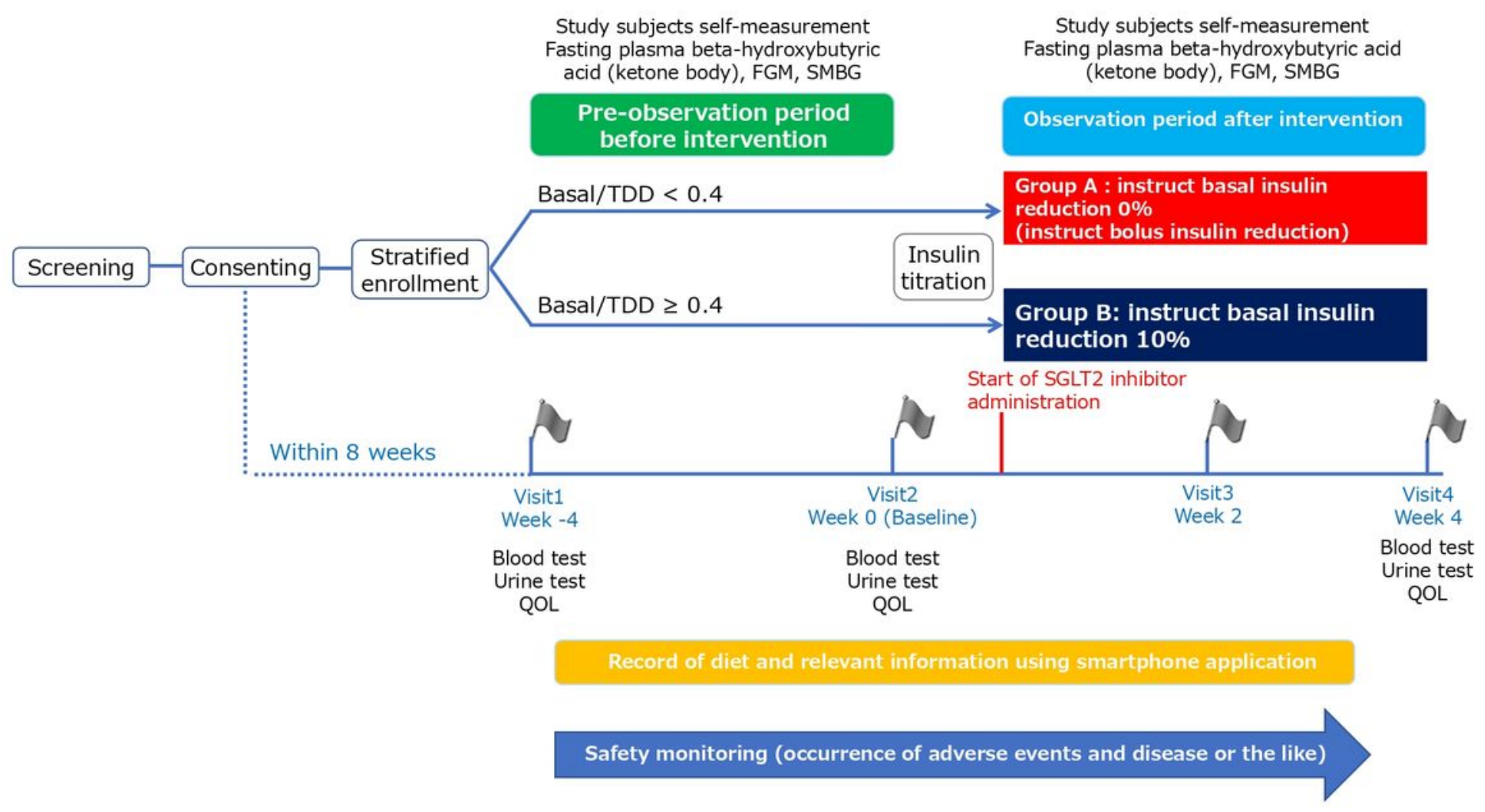

\section{Figure 1}

The study design The study subjects are stratified into two groups based on the ratio of basal insulin (Basal) to the total daily insulin dose (TDD) (Basal/TDD, $<0.4$ or $>0.4$ ). The study does not involve randomization of participants. 


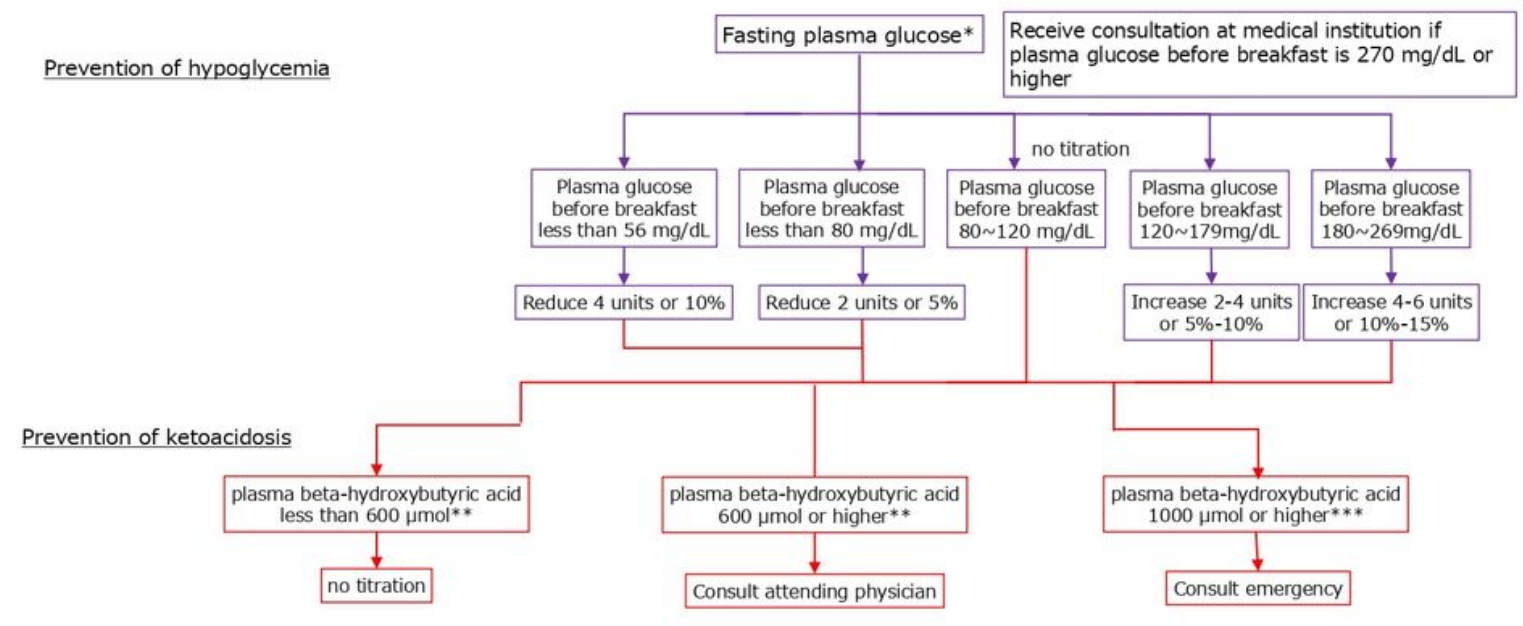

\section{Figure 2}

Algorism for Basal Insulin Titration after SGLT2 administration The study subjects are to follow the dosing instruction for 3 days from the start of the intervention after which the basal and bolus insulin can be titrated either by the subject or by instruction from the attending physician according to "Algorithm for Basal Insulin Titration after SGLT2 administration." 


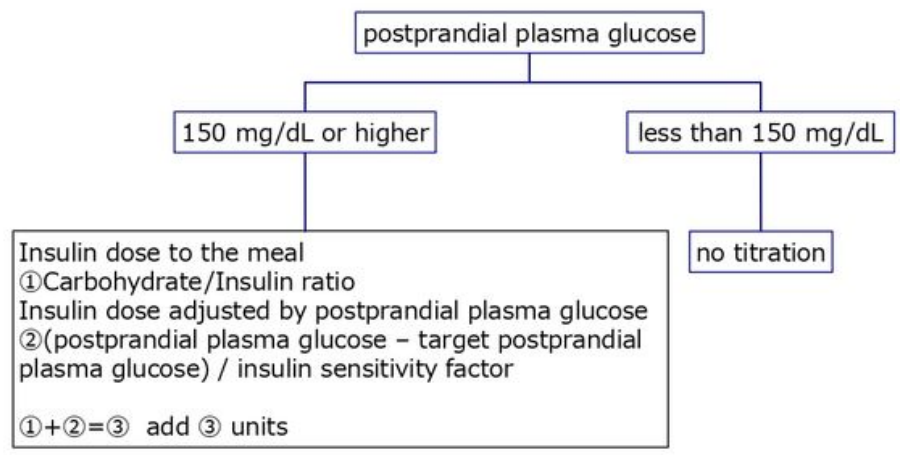

\section{Figure 3}

Algorism for Bolus Insulin Titration after SGLT2 administration The study subjects are to follow the dosing instruction for 3 days from the start of the intervention after which the basal and bolus insulin could be titrated either by the subject or by instruction from the attending physician according to "Algorithm for Bolus Insulin Titration after SGLT2 administration 


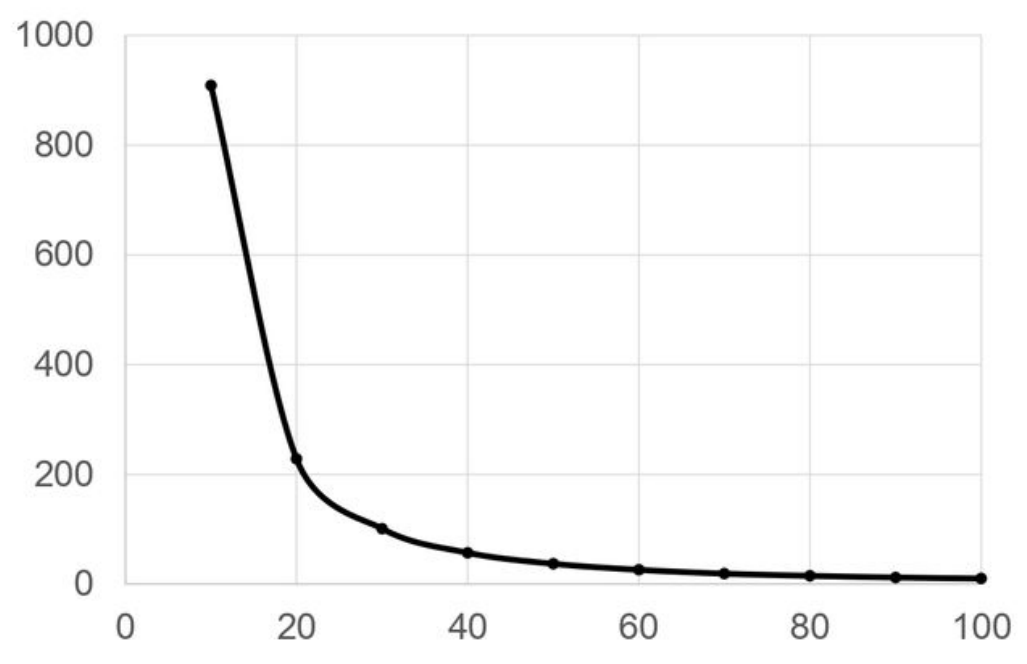

\section{Figure 4}

The assumed increase of hypoglycemia and required sample size The baseline hypoglycemia was set as $7 \pm 6$ times/month. Increase of hypoglycemia is expressed as \% increase from the baseline (shown in $X$ axis). The minimum sample size required to achieve a significance of 0.05 for a one-sided t-test with a statistical power at $80 \%$ is determined. The necessary sample size is expressed as number of patients in one arm (shown in Y axis). When sample size is 29 patients in one group, \% increase of the hypoglycemia was more than $60 \%$, the sample size is estimated to be enough.

\section{Supplementary Files}

This is a list of supplementary files associated with this preprint. Click to download.

- CONSORTAbstractsChecklistr4.pdf

- CONSORTFlowDiagramr4.pdf

- Supr4.pdf 